\title{
Neonatal Pneumothorax - 10 Years of Experience From a Single Center
}

\author{
圆 Mustafa Okumuş1，四Adil Umut Zubarioğlu2 \\ ${ }^{1 Y e n i}$ Yüzyıl University Faculty of Medicine, Department of Pediatric Surgery, İstanbul, Turkey \\ ${ }^{2}$ Yeni Yüzyıl University Faculty of Medicine, Department of Pediatrics, Division of Neonatology, İstanbul, Turkey
}

\begin{abstract}
Aim: Pneumothorax is detected in approximately $1-2 \%$ of all term newborns and this rate can reach $15-20 \%$ in neonatal intensive care unit (NICU)'s; tube thoracostomy (TT) is the traditional treatment in symptomatic newborns. The management of neonatal pneumothorax, and etiologies, and risk factors related to mortality were evaluated in this study.

Materials and Methods: A total of 6.647 newborns who were treated in the NICU during the last ten years were evaluated retrospectively. Newborns with pneumothorax were included in the study. Demographic characteristics, treatment modalities, and outcomes were evaluated.

Results: Pneumothorax was diagnosed in $124(1.9 \%)$ newborns. The mean gestational age was $33.3 \pm 5.1$ weeks and the mean birth weight was 2,163.7 \pm 899.4 grams; 101 (81\%) were preterm and 40 (32\%) were very low birth weight newborns. Seventy-four (58\%) newborns were diagnosed as having Respiratory Distress syndrome, the diagnosis was transient tachypnea of the newborn in 43 (35\%), Meconium Aspiration syndrome in $3(2.5 \%)$ and pneumonia in $4(3 \%)$. One hundred nineteen newborns were treated with TT. Spontaneous resolution was observed in five newborns with close follow-up. A total of 129 (bilateral pneumothorax in 20 newborns) tube thoracostomies were performed at the bedside with no major complication. The overall mortality rate was found to be $21 \%$. Gestational ages were 33 weeks or less in 25 of the 26 deaths.

Conclusion: Very low birth weight and prematurity in neonatal pneumothorax are associated with mechanical ventilation necessity and mortality. TT with small-bore chest drains is safe and effective in the management.
\end{abstract}

Keywords: Newborn, pneumothorax, tube thoracostomy, pulmonary air leak

\section{Introduction}

Pneumothorax is an Air Leak syndrome that occurs when air leaks between the visceral and parietal pleural surfaces. It occurs more frequently in the newborn period, particularly in ventilated, low birth weight newborns (1). Although spontaneous pneumothorax (without any obvious lung diseases) is present in 1-2\% of all term newborns, the rate of pneumothorax increases to up to $15-20 \%$ in the neonatal intensive care unit (NICU) due to underlying lung pathologies such as Respiratory Distress syndrome
(RDS) and transient tachypnea of the newborn (TTN) $(1,2)$. The management of pneumothorax has traditionally been through tube thoracostomy (TT). When the effectiveness of small-bore catheters was proven, conventional largebore chest tubes were no longer used in newborns (3). Small-bore pigtail catheters via the Seldinger route and catheters with a trocar needle are frequently used in many centers $(4,5)$. The etiologies and risk factors related to neonatal pneumothorax, and also treatment modalities were evaluated in this study. 


\section{Materials and Methods}

Following approval from the institutional review board (Yeni Yüzyıl University, Clinical Research Ethical Committee; 2018/02), a total of 6,647 newborns who were treated in the NICU between January $1^{\text {st }}, 2007$, and January $1^{\text {st }}, 2017$, were evaluated retrospectively. Newborns with pneumothorax were included in the study. The demographic characteristics of the newborns and their outcomes were evaluated. TT using small-bore chest drains with a trocar needle was the only treatment modality. Eight-french drains were used for very low birth weight (VLBW) newborns ( $\leq 1.500$ grams) and $10 \mathrm{~F}$ for all others. All tube thoracostomies were performed at the bedside by the same pediatric surgeon. The position of the drain was confirmed radiologically. The demographic characteristics of the newborns and their outcomes were evaluated.

\section{Statistical Analysis}

Statistical analysis was performed using the SPSS 21.0 package program (AIMS, Istanbul, Turkey). Descriptive data are expressed as mean \pm standard deviation and number (\%). Continuous variables are given as mean \pm standard deviation and categorical variables as number (\%). The Shapiro-Wilk test was used to investigate which variables among the groups were normally distributed. Independent group comparisons were made using Student's t-test when parametric test assumptions were provided. The Mann-Whitney $U$ test was used when parametric test assumptions were not provided. The chi-square test was used to determine categorical variables. P values $<0.05$ were considered statistically significant.

\begin{tabular}{|c|c|c|}
\hline & $\mathbf{n}$ & $\%$ \\
\hline Preterm & 101 & 81 \\
\hline Term & 23 & 19 \\
\hline$\leq 1.500$ grams & 40 & 32 \\
\hline$>1.500$ grams & 84 & 68 \\
\hline Right sided & 85 & 69 \\
\hline Left sided & 19 & 15 \\
\hline Bilateral & 20 & 16 \\
\hline RDS & 74 & 60 \\
\hline TTN & 43 & 35 \\
\hline MAS & 3 & 2.5 \\
\hline Pneumonia & 4 & 3 \\
\hline \multicolumn{3}{|c|}{$\begin{array}{l}\text { RDS: Respiratory Distress syndrome, TTN: Transient tachypnea of the newborn, } \\
\text { MAS: Meconium aspiration syndrome }\end{array}$} \\
\hline
\end{tabular}

\section{Results}

Pneumothorax was detected in 124 (1.9\%) newborns. Ninety-eight newborns (79\%) were delivered by cesarean section and 80 (65\%) newborns were male. The mean gestational age was $33.3 \pm 5.1$ weeks and the mean birth weight was 2,163.7 \pm 899.4 grams; 101 (81\%) were preterm and 40 (32\%) were with VLBW newborns. Other characteristics are shown in Table I. All diagnoses were confirmed through chest X-ray (CXR). TT was the primary treatment modality in 119 newborns. Spontaneous resolution was observed in five newborns with close follow-up.

A total of 129 TT procedures were performed in 119 newborns because of bilateral involvement. The mean TT duration was $3.4 \pm 1.6$ days. The durations for newborns with and without mechanical ventilation were considered as $3.7 \pm 1.7$ days and $3.0 \pm 1.3$ days, respectively $(p=0.017)$. There were no major complications or deaths detected in the early or late period due to TT. Short-term bleeding in three newborns and one tube dislodgement were detected as minor complications. A second thorax tube was not required in the series. Suction was applied for 1-2 days for 12 newborns who did not benefit from gravity water seal drainage. The treatment flow chart is shown in Figure 1.

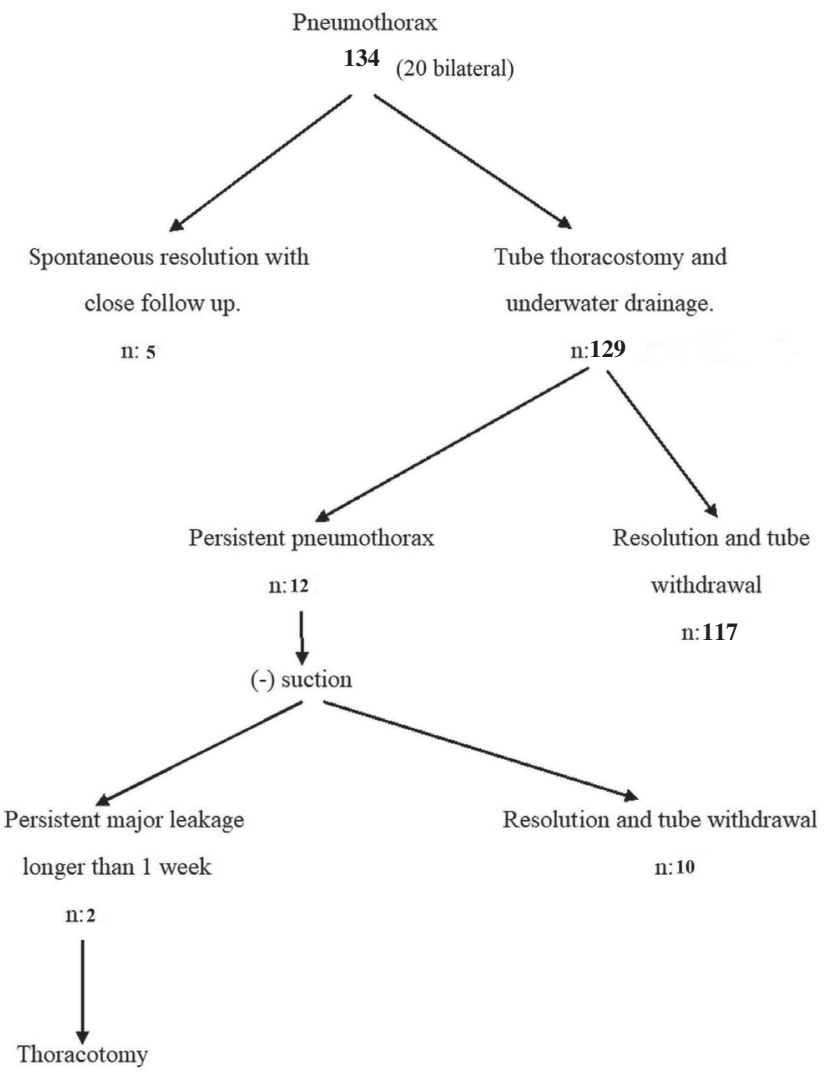

Figure 1. Treatment flow chart 
The overall mortality rate was found as $21 \%(n=26)$. The mortality rate and the necessity of ventilatory support and surfactant therapy were significantly increased with VLBW (Table II). All deaths occurred in preterm newborns. Their gestational ages were 33 weeks or less in 25 of the 26 deaths. Furthermore, 22 of them had VLBW (intraventricular hemorrhage: 10, chronic lung disease: 7, sepsis: 7, congenital heart disease: 2). In two preterm newborns with weights of 800 and 1,200 grams, the air leak continued for more than a week without reducing. Thoracotomy and fistula repair were performed on the $8^{\text {th }}$ and $10^{\text {th }}$ days for these two newborns. Fistulas were found in the anterobasal segment of the right lower lobe and were not considered as TT complications. For both newborns, the thoracic tubes were removed on the fourth day and they were discharged after treatment of their primary problems.

\section{Discussion}

Pneumothorax in the newborn results in significant morbidity and mortality. It is detected in approximately $1-2 \%$ of all term newborns and this rate can reach $15-20 \%$ in the NICU. Prematurity, underlying diseases, low birth weight and mechanical ventilation are the major risk factors of pneumothorax in NICU admissions. All positive pressure ventilation modes play an important role in the etiology. Prolonged inspiratory time, high mean airway pressure, poor patient synchronization with the ventilator, and continuous positive airway pressure are other etiologic factors $(1,2)$. Maximal peak inspiratory pressure and the number of suction procedures are also associated with pneumothorax in low birth weight newborns $(6,7)$. Furthermore, cesarean section was shown to be a predisposing factor for neonatal pneumothorax related to catecholamine discharge in some studies $(8,9)$.

We followed up 6,647 newborns in the NICU over ten years and observed only 124 (1.9\%) cases of pneumothorax. Watkinson and Tiron reported that $8.7 \%$ of ventilated neonates developed at least one pneumothorax during the first two weeks of life (10). A higher incidence of 10\%-13.4\% has been reported by studies from the United Kingdom and an incidence of $26 \%$ by Malek et al. from Iran (11-13). When there are values of up to $20 \%$ in the literature, it is difficult to explain the difference. However, this low incidence refers to pooled neonates of low and normal body weight and also preterm and term infants with or without positive pressure ventilatory support together. In addition, we could say that it must be related to the use of surfactants, neuromuscular blocking agents, and fast ventilator rates (1).

These results are supported by the fact that $79 \%$ of our newborns were delivered by cesarean section, $56.5 \%$ were on mechanical ventilation, $81 \%$ were preterm and $32 \%$ with VLBW. RDS, TTN, and meconium aspiration syndrome constituting the majority of underlying diseases in the series.

The slight male (65\%) and right-side (69\%) predominance in our series were in accordance with the literature (14). The flat angle of the right main bronchus and malposition of the endotracheal tube down to the right main bronchus or perforation by suction catheter may be the main causes of right-sided pneumothorax.

Pneumothorax should be suspected in any newborn with respiratory distress or in those with ventilatory support whose condition suddenly worsens. A high index of suspicion is needed to diagnose pneumothorax. The diagnosis is confirmed with CXR and should be performed on all newborns if there is adequate time. Occasionally, transillumination and lung ultrasonography may be helpful (15-17). If these are not available to help the diagnosis, direct needle aspiration can be a good alternative for diagnosis and also treatment $(18,19)$. The goal should be to evacuate the air from the pleural space, ensure complete pulmonary re-expansion, and restore respiratory mechanics (20).

Although some literature states that there is no need for intervention in almost half of all spontaneous primary pneumothorax cases (term newborn without any obvious lung disease), we were able to follow up only five of our newborns without any intervention $(1,2)$. This may be due to the fact that many of our newborns were preterm with low birth weight and had ventilatory support. Nevertheless, it should be kept in mind that fearing complications of TT and waiting for more clinical deterioration might be more harmful.

Table II. Association with very low birth weight and mortality

\begin{tabular}{|c|c|c|c|c|}
\hline & $\begin{array}{l}\text { Total number of } \\
\text { patients } n=124(\%)\end{array}$ & $\begin{array}{l}\text { Birth weight } \leq 1.500 \mathrm{~g} \\
\mathrm{n}=40(\%)\end{array}$ & $\begin{array}{l}\text { Birth weight }>1.500 \\
n=84(\%)\end{array}$ & $\mathbf{p}$ \\
\hline Mechanical ventilation & $70(56.5)$ & $38(95)$ & $32(38)$ & $p<0.001$ \\
\hline Surfactant therapy & $55(44)$ & $33(82.5)$ & $22(26)$ & $p<0.001$ \\
\hline Mortality & $26(21)$ & $22(55)$ & $4(4.7)$ & $p<0.001$ \\
\hline
\end{tabular}


TT complications, especially with classic large-bore TT, are frequently mentioned in the literature (e.g., hemorrhage, parenchymal laceration, damage to breast tissue, damage to deeper structures or infection). When the efficacy of small-bore catheters was recognized, pigtail catheters and catheters with trocar needles started to be used in many centers with great success $(4,5)$. Such catheters have been shown to be as effective as and less invasive than traditional chest tubes $(4,18-21)$. If we consider that there would be no improvement with conservative management, we do not hesitate to perform TT with a small-bore chest drain (with trocar needle). We performed TT on all newborns except five (119 newborns, 129 tube thoracostomies). Single needle aspiration was not used as a primary attempt because most of them were tension pneumothorax. We think that there is no difference between small-bore TT and needle aspiration not only in terms of difficulty but also regarding complications. We had no major complications due to tube thoracostomies as stated above. The mean TT duration was 3.41 days and mechanical ventilation increased the duration of TT. The reason for this increase may be a separate discussion topic. It is a fact that we were a little slow to withdraw the tube in newborns with ventilatory support.

Suction can sometimes be applied to speed up the removal of air and to favor complete re-expansion of the lung $\left(-10,-20 \mathrm{~cm} \mathrm{H}_{2} \mathrm{O}\right)$. Despite these obvious advantages, some surgeons believe that suction contributes to prolonged air leaks (20). Air leaks that persist for more than a week may need to be treated surgically (2). Alternatively, some success has been reported with conservative management, including the installation of fibrin glue, povidone-iodine via chest tube or selective bronchial intubation of the contralateral side $(21,22)$. We had two newborns (800gram and 1,200-gram preterm newborns) in whom air leaks continued for more than a week. We preferred to perform thoracotomy and fistula repair. The chest tubes were withdrawn on the fourth day without any problems in either of them.

A mortality of $10 \%$ to $43 \%$ with neonatal pneumothorax has been reported by various studies; Malek et al. (13) $40.8 \%$, Bahatia et al. (23) 43\%. Mortality often depends on other underlying factors rather than pneumothorax per se $(24,25)$. Although Malek et al. (13) reported that the mortality rate after developing pneumothorax was $40.8 \%$ compared with $32 \%$ in the control group, which was not significantly different in newborns on ventilatory support, Bhat et al. (24) stated that mortality among ventilated newborns with pneumothorax was nearly twice that of newborns without pneumothorax (25). It is a predictable outcome that this rate is higher among with VLBW and preterm newborns. Mechanical ventilation necessity, VLBW, prematurity, intraventricular hemorrhage, chronic lung diseases and sepsis are the major causes of mortality $(26,27)$. The overall mortality rate was $21 \%$ in this series and 22 of 26 deaths occurred in very VLBW newborns. While those newborns weighing less than 1,500 grams had a mortality rate of $55 \%$, the birth weight was below 1,000 grams in 10 newborns.

\section{Conclusion}

Pneumothorax is still associated with high mortality and morbidity. VLBW and prematurity in neonatal pneumothorax are associated with mechanical ventilation necessity and mortality. If pneumothorax causes only minor symptoms, no specific therapy is required, but the infant's color, heart rate, respiratory rate, blood pressure, and oxygenation should be monitored. If severe respiratory distress is noted, the air in the pleural cavity should be drained. TT with smallbore chest drains is safe and effective in the management.

\section{Ethics}

Ethics Committee Approval: The study was approved by the Ethics Committee of Yeni Yüzyıl University Medical Faculty (approval number: 2018/02).

Informed Consent: Informed consent is not required for this type of study.

Peer-review: Enternally peer-reviewed.

\section{Authorship Contributions}

Concept: M.O., Design: M.O., A.U.Z., Data Collection or Processing: M.O., A.U.Z. Analysis or Interpretation: M.O., A.U.Z., Literature Search: M.O., A.U.Z., Writing: M.O.

Conflict of Interest: The authors have no conflict of interest to declare.

Financial Disclosure: There are no financial relationships relevant to this article to disclose.

\section{References}

1. Greenough A, Bhojnagarwala B. Causes, and management of pulmonary air leaks. Paediatr Child Health 2012;12:523-7.

2. Hafis Ibrahim CP, Ganesan K, Mann G, et al. Causes and management of pulmonary air leak in newborns. Paediatr Child Health 2009;4:165-70.

3. Reed MF, Lyons JM, Luchette FA, et al. Preliminary report of a prospective randomized trial of underwater seal for spontaneous and iatrogenic pneumothorax. I Am Coll Surg 2007;204:84-90.

4. Wei YH, Lee $\mathrm{CH}$, Cheng HN, Tsao LT, Hsiao CC. Pigtail catheters versus traditional chest tubes for pneumothoraces in premature 
newborns treated in a neonatal intensive care unit. Pediatr Neonatol 2014;55:376-80.

5. McElnay PJ, Lim E. Modern techniques to insert chest drains. Thorac Surg Clin 2017;27;29-34.

6. Miller JD, Waldemar A, Carlo A. Pulmonary complications of mechanical ventilation in neonates. Clin Perinatol 2008;35:27381.

7. Gonzalez PP, Garcia JF, Canfran S, et al. Neonatal pneumothorax pressures surpass higher threshold in lung recruitment maneuvers. Respir Care 2016;2:142-8.

8. Lai $Y$, Chia $Y$, Wen $\mathrm{C}$, Hsu $\mathrm{H}$, Chang $\mathrm{H}$, Huang W. Association between the risk of neonatal pneumothorax and mode of anesthesia for cesarean delivery at term: a nationwide population-based retrospective cohort study. Int I Obstet Anesth 2017;30:80-1.

9. Zanardo V, Padovani E, Pittini C, Doglioni N, Ferrante A, Trevisanuto $D$. The influence of timing of elective cesarean section on risk of neonatal pneumothorax. I Pediatr 2007;3:2525.

10. Watkinson M, Tiron I. Events before the diagnosis of a pneumothorax in ventilated neonates. Arch Dis Child 2001;85:201-3.

11. Baumer J.H. International randomized controlled trial of patient triggered ventilation in neonatal respiratory distress syndrome. Arch Dis Child 2000;82:5-10.

12. Shaw NJ, Cooke RW, Gill AB, Shaw NJ, Saeed M. Randomized trial of routine versus selective paralysis during ventilation for neonatal respiratory distress syndrome. Arch Dis Child 1993;69:479-82.

13. Malek A, Afzali N, Meshkat M, Yazdi NH. Pneumothorax after mechanical ventilation in newborns. Iran J Pediatr 2011;21:45-50.

14. Illçe Z, Gündoğdu G, Kara C, llikkan B, Celayir S. Which patients are at risk? Evaluation of the morbidity and mortality in newborn pneumothorax. Indian Pediatr 2003;40:325-8.

15. Cizmeci MN, Kanburoglu MK, Akelma AZ, Andan H, Akin K, Tatli MM. An abrupt increment in the respiratory rate is a sign of neonatal pneumothorax. I Matern Fetal Neonatal Med 2015;28:583-7.
16. Light RW. Neonatal pneumothorax. In: Broaddus VC, Mason RJ. Editors. Murray and Nadel's Textbook of Respiratory Medicine. 6th edition. Philadelphia: Saunders. 2016 p:1448-9.

17. Cattarossi L, Copetti R, Brusa G, Pintaldi S. Lung ultrasound diagnostic accuracy in neonatal pneumothorax. Can Respir I 2016;2016:6515069.

18. Arda IS, Gürakan B, Aliefendioglu D, Tüzün M. Treatment of pneumothorax in newborns: use of venous catheter versus chest tube. Pediatr Int 2002;44:78-82.

19. Bruschettini $M$, Romantsik $O$, Ramenghi LA, Zappettini $S$, O'Donnell CP, Calevo MG. Needle aspiration versus intercostal tube drainage for pneumothorax in newborn. Cochrane Database Syst Rev 2016;CD011724.

20. Venuta F, Diso D, Anile M, Rendina EA, Onorati I. Chest tubes: generalities. Thorac Surg Clin 2017;27:1-5.

21. Vicente EG, Espelata FT, Gimeno OL, et al. Resolved tension pneumothorax in a newborn with an adult Heimlich valve. Resuscitation 2008;77:294-5.

22. Arayıc S, Kadioglu GS, Oncel MY, Yilmaz Y, Canpolat FE, Dilmen $U$. Povidone-iodine for a persistent air leak in an extremely low birth weight infant. J Pediatr Surg 2013;48:21-3.

23. Bahatia R, Davis PG, Doyle LW, Wong C, Morley C). Identification of pneumothorax in very preterm infants. J Pediatr 2016;159;11521.

24. Bhat Yellanthoor R, Ramdas V. Frequency and intensive care related risk factors of pneumothorax in ventilated neonates. Pulm Med 2014;2014:727323.

25. Aly $H$, Massaro A, Acun C, Ozen M. Pneumothorax in the newborn: clinical presentation, risk factors and outcomes. I Matern Fetal Neonatal Med 2014;27:402-6.

26. Ali R, Ahmed S, Qadir M, Maheshwari P, Khan R. Pneumothoraces in a neonatal tertiary care unit: case series. Oman Med 2013;28:67-9.

27. Trevisanuto $D$, Doglioni $N$, Ferrarese $P$, Vedovato $S$, Cosmi E, Zanardo V. Neonatal pneumothorax: comparison between neonatal transfers and inborn newborns. I Perinat Med 2005;33:449-54. 